\title{
Combined right thoracotomy and left video-assisted thoracoscopic surgery for left tracheal sleeve pneumonectomy: a case report
}

\author{
Marco Mammana ${ }^{1}$, Giovanni M. Comacchio ${ }^{1}$, Alessandro Pangoni ${ }^{1}$, Andrea Zuin ${ }^{1}$, Samuele Nicotra ${ }^{1}$, \\ Chiara Giraudo ${ }^{2}$, Federico Rea ${ }^{1}$ \\ ${ }^{1}$ Thoracic Surgery Unit, Department of Cardiac, Thoracic, Vascular Sciences and Public Health, University of Padua, Padua, Italy; ${ }^{2}$ Radiology Unit, \\ Department of Medicine - DIMED, University of Padua, Padua, Italy \\ Correspondence to: Marco Mammana, MD. Thoracic Surgery Unit, Department of Cardiac, Thoracic, Vascular Sciences and Public Health, University \\ of Padua, Via Giustiniani, 2, 35128, Padua, Italy. Email: marcomammana87@gmail.com.
}

\begin{abstract}
Left tracheal sleeve pneumonectomy (LTSP) is a challenging operation and traditional surgical approaches have their downsides. We describe the case of a 38-year-old patient affected by adenoid cystic carcinoma of the left main bronchus and the carina who underwent surgical excision of his tumor through a bilateral approach. En bloc tumor and carinal resection, followed by right main bronchial reimplantation were performed through right thoracotomy; while the left pneumonectomy was completed through a contralateral uniportal thoracoscopic approach. This is the seventh reported case of LTSP performed through a combined open and thoracoscopic approach. Some details, such as the side of the operation to approach first and the method of intraoperative ventilation, vary between reports; however, globally, the reported outcomes seem favorable. The growing number of published cases suggests that such approach should be acknowledged as a reasonable alternative to traditional surgical accesses for LTSP.
\end{abstract}

Keywords: Pneumonectomy; video-assisted thoracoscopic surgery (VATS); high-frequency jet ventilation; case report

Received: 11 March 2020; Accepted: 01 July 2020; Published: 20 July 2021.

doi: 10.21037 /jovs-2020-10

View this article at: http://dx.doi.org/10.21037/jovs-2020-10

\section{Introduction}

Left tracheal sleeve pneumonectomy (LTSP) is one of the most challenging thoracic surgical procedures. Traditional operative approaches include left thoracotomy and median sternotomy; each of them, however, has its downsides: access to the carina from the left side, in fact, is limited by the presence of the aortic arch, while median sternotomy, with opening of the transpericardial route, is a feasible approach, although the surgical field is narrowed by the presence of the aorta, superior vena cava and right pulmonary artery, and access to the left pleural cavity is suboptimal (1).

It is intuitive that a bilateral approach offers the most suitable conditions to perform the left pneumonectomy on one side and the reimplantation of the right main bronchus on the other side; however, the morbidity associated with a double thoracotomy or a clamshell incision is considerable. Therefore, since the advent of thoracoscopy, some authors have hypothesized that a combined thoracoscopic and open approach would have been convenient for performing LTSP (2). Nevertheless, given the rarity of this procedure, such a strategy has been only anecdotally reported $(3,4)$. In the present paper, we document the case of aLTSP performed through a combined thoracoscopic and open approach, and we provide a review of all similar published reports.

We present the following case in accordance with the CARE reporting checklist (available at https://jovs. amegroups.com/article/view/10.21037/jovs-2020-10/rc). 

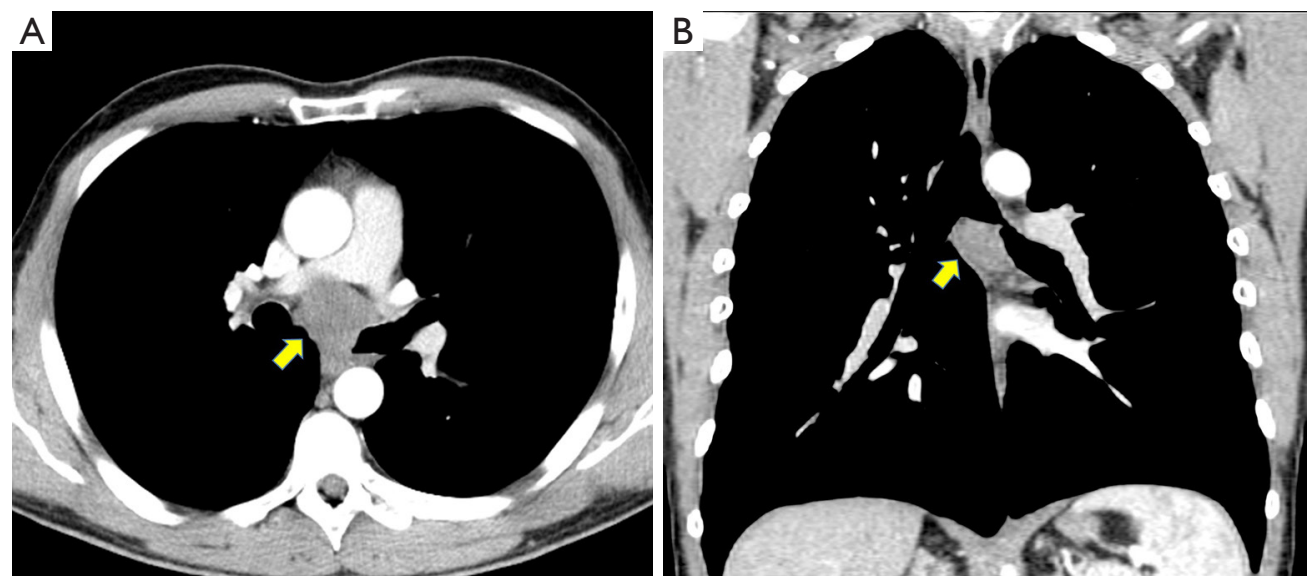

Figure 1 Computed tomography findings. (A) Axial and (B) Coronal view. Arrows indicate the tumor.

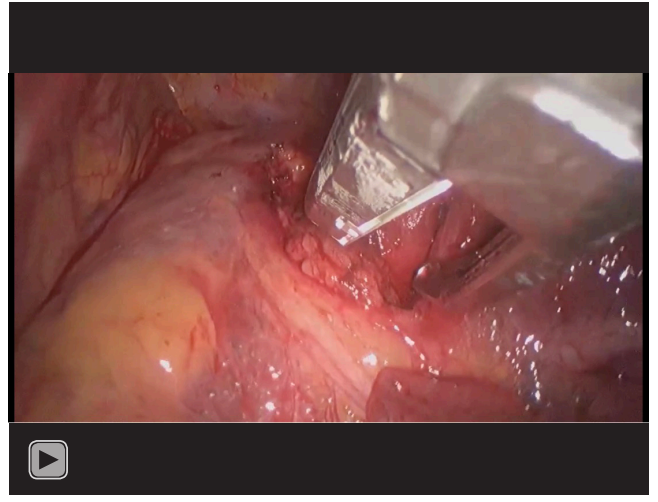

Video 1 Unilateral thoracoscopic view of the left pneumonectomy. In sequence it is possible to appreciate the isolation and division, by means of a mechanical stapler, of the left main pulmonary artery and of the superior and inferior left pulmonary veins. Finally, the stump of the left main bronchus, previously divided, is extracted from the mediastinum.

\section{Case presentation}

A 38-year-old man, nonsmoker, with persistent cough and dyspnea, was found with an endoluminal lesion of the left mainstem bronchus with subcarinal extension, measuring $4.5 \mathrm{~cm}$ in its largest diameter at CT scan (Figure 1). The patient subsequently underwent PET-CT scan, which revealed a pathologic uptake limited to the tumor $\left(\mathrm{SUV}_{\max } 3\right)$. Rigid bronchoscopy documented a nearly total obstruction of the left main bronchial orifice by the mass, which was successfully cored out during the same procedure. The lesion originated $1 \mathrm{~cm}$ proximally to the carina and extended down to the division between upper and lower lobe bronchi (Figure 1B). Pathology report concluded for adenoid cystic carcinoma.

Given the lack of distant metastases and the good clinical conditions of the patient, decision was made for surgery. Unfortunately, the left mainstem bronchus was involved for almost its entire length, which precluded the possibility of sparing the left lung; additionally, due to the extension of the mass into the subcarinal region, a difficult dissection of the right main bronchus and of the right main branch of the pulmonary artery was anticipated (Figure 1A). Therefore, the planned surgical procedure consisted of aLTSP through bilateral sequential right thoracotomy and left thoracoscopy (Video 1).

Under general anesthesia and independent lung ventilation, provided by a left double-lumen endotracheal tube, the patient was positioned in left lateral decubitus and a right thoracotomy was performed into the 4th intercostal space. Intraoperatively, the posterior aspect of the carina was exposed, and the mass was carefully dissected from surrounding structures, including right main bronchus, right main pulmonary artery, azygos vein and esophagus. Afterwards, the distal trachea and both main bronchi were divided in tumor-free zones to allow excision of the tumor and cross-field intubation of the left main bronchus was performed (Figure 2A,B). After that frozen section examination confirmed the negativity of resection margins, the right main bronchus was reimplanted into the distal trachea by means of a termino-terminal anastomosis with interrupted 3-0 Vicryl sutures (Figure 2C), while the patient was still ventilated through the left main bronchus. On completion of the anastomosis, a standard single-lumen endotracheal tube 

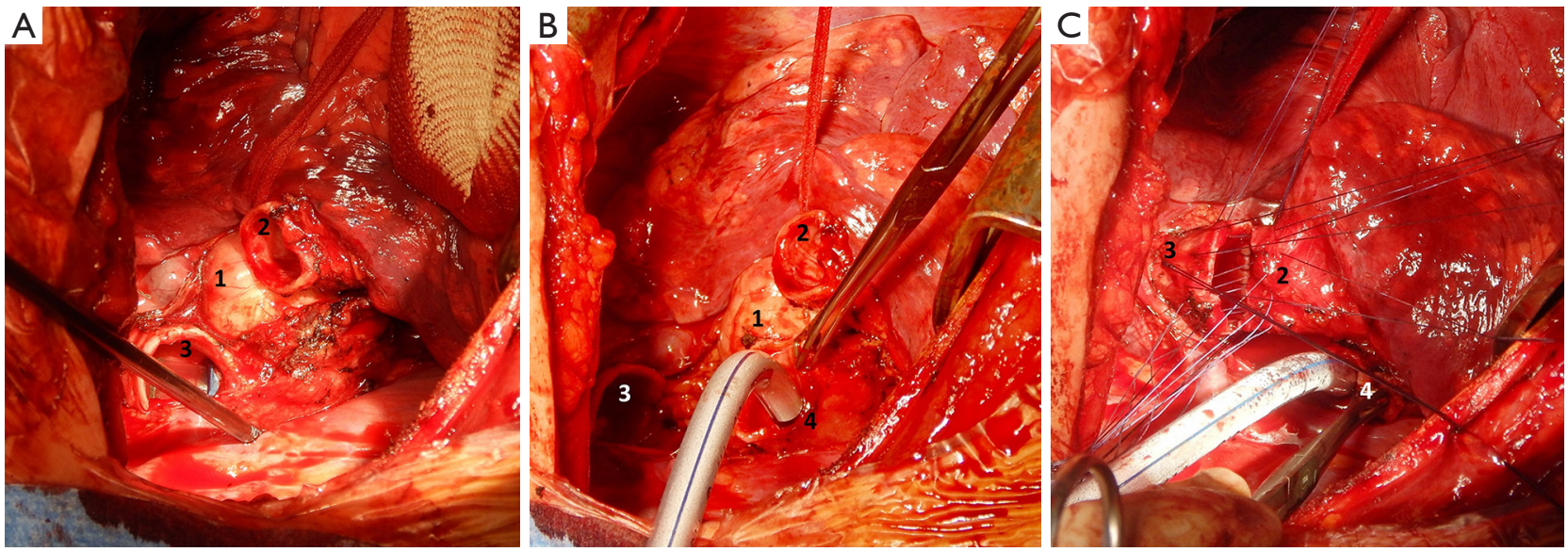

Figure 2 Intraoperative view. (A) Right main bronchus is divided; the left-sided double-lumen tube is visible through the tracheal lumen. (B) Distal trachea and left main bronchus are divided; cross-field intubation into the left main bronchus is established. (C) After resection of the tumor a termino-terminal anastomosis between distal trachea and right main bronchus is performed. Ventilation is maintained through left main bronchial intubation (1: tumor, 2: right main bronchus, 3: trachea, 4: left main bronchus).

was positioned above the suture line, and a flap of thymic tissue was wrapped around the anastomosis. Finally, the left bronchial stump was sutured and plunged down into the mediastinum, and the right pleural cavity was closed and drained by a single chest tube.

For the second step of the operation, the patient was repositioned in a right lateral decubitus and a single 4-cm thoracoscopic incision on the anterior axillary line was performed (Figure 3A); this allowed to safely complete the left pneumonectomy and a systematic left hilar and mediastinal lymphadenectomy. Total operative time was 305 minutes, including 210 minutes for the right side and 95 minutes for the left side. Total blood loss was $200 \mathrm{cc}$ and the patient were extubated in the operating room. The postoperative course was uneventful; intensive care unit stay was 2 days, while total postoperative hospital stay was 14 days. Final pathologic examination confirmed adenoid cystic carcinoma pT4(inv)N0, with free resection margins. Scheduled bronchoscopic examinations were performed on postoperative day 1 , day 7 , and one month thereafter, documenting a regular anastomosis (Figure $3 B$ ). At the time of writing this report, the patient is alive and disease-free after 13 months from his surgery.

Written informed consent was obtained from the patient for publication of this study and any accompanying images. A copy of the written consent is available for review by the Editor-in-Chief of this journal. All procedures performed in this study were in accordance with the Helsinki Declaration (as revised in 2013).

\section{Discussion}

The choice of the surgical approach for LTSP is of critical importance. The convenience of a bilateral approach, in fact, must be weighed against the need for a reduced surgical invasiveness, due to the known high rates of morbidity and mortality that characterize this procedure (5).

Probably, in uncomplicated cases, median sternotomy is the access of choice, in that it provides an adequate surgical field and is associated with acceptable postoperative morbidity. However, in this particular patient, the use of a bilateral approach was justified by extension of the tumor along the medial and posterior aspects of the right main bronchus and the posterior aspect of the pulmonary artery (Figure 1), and the consequent need for an adequate exposure for dissection of these structures.

Other authors have described the use of VATS in combination with thoracotomy to perform LTSP. Table 1 provides a synopsis with the main characteristics of all published cases.

In most reports, the patient underwent some form of endoscopic intervention prior to surgery. Unblocking of the left main bronchus, by either laser-assisted ablation, mechanical coring out or temporary stent placement (4), greatly facilitates airway management during the operation; in the present case, in fact, both the left-sided double lumen endotracheal intubation and the left cross-field intubation of the left main bronchus were used at different phases of the procedure. This highlights the importance of rigid endoscopy 

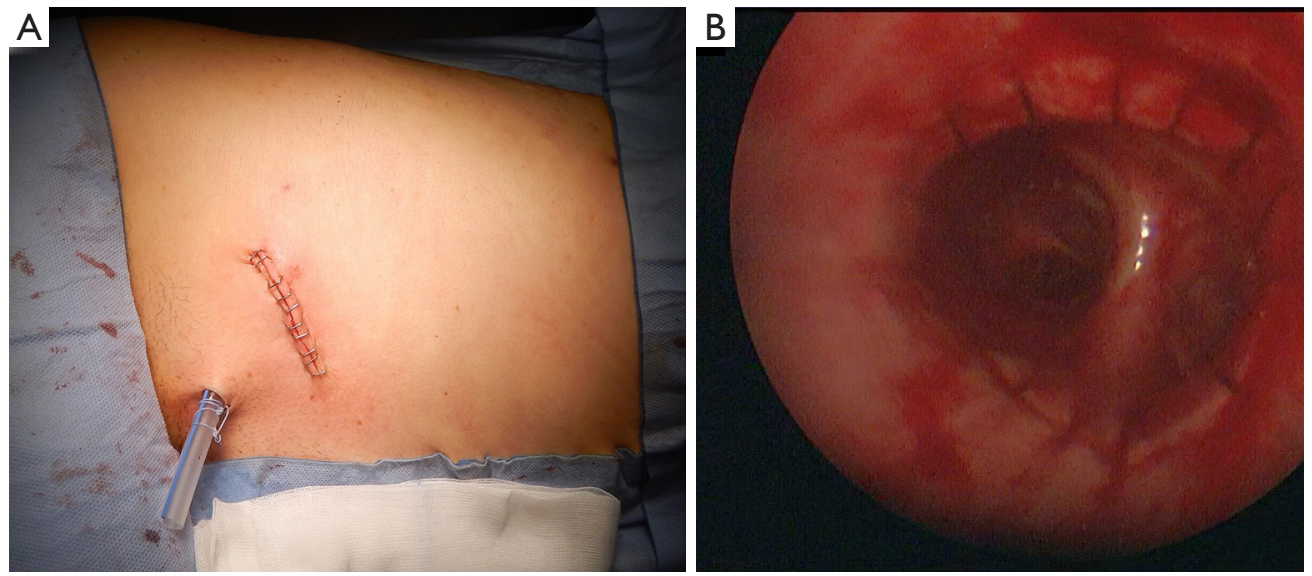

Figure 3 Postoperative results. (A) Skin incision for left VATS; (B) bronchoscopy at postoperative day 1.

Table 1 Bilateral combined approaches for LTSP, review of the literature

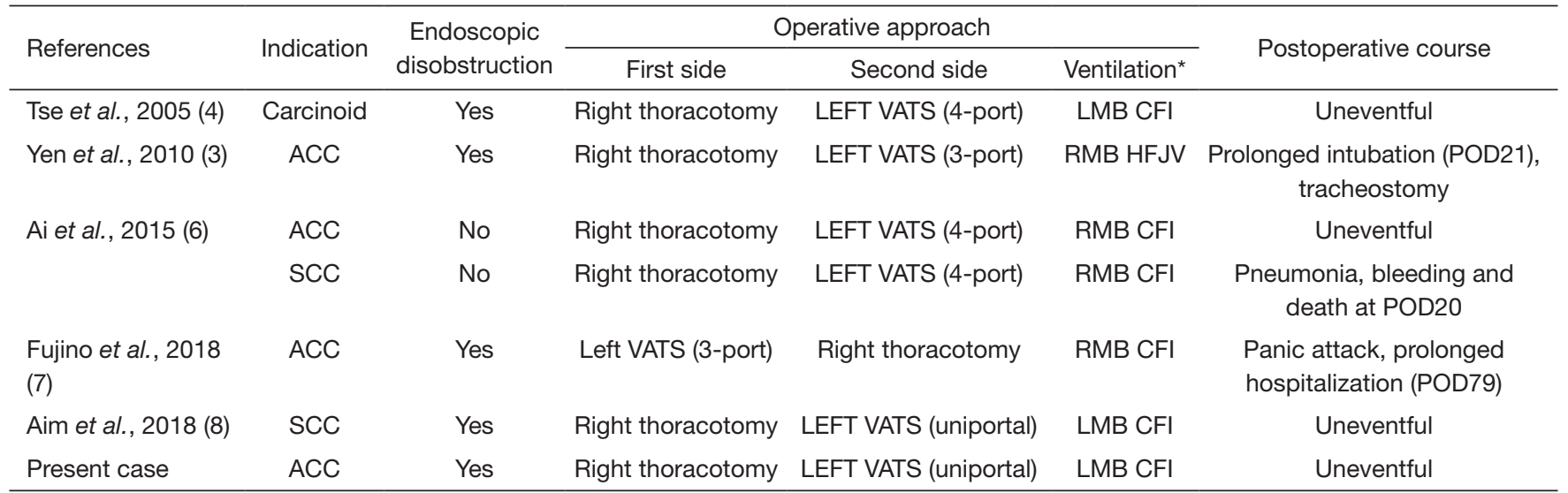

*, during carinal resection and anastomosis of right main bronchus. R, right; L, left; VATS, video-assisted thoracoscopic surgery; LMB, left main bronchus; RMB, right main bronchus; CFI, cross-field intubation; HFJV, high frequency jet ventilation; ACC, adenoid cystic carcinoma; SCC, squamous cell carcinoma; POD, post-operative day.

in the management of tumors involving the carina.

In the other reported cases, the combined approach consisted most often of a right thoracotomy first, for carinal resection and reimplantation of the right main bronchus, and a subsequent left VATS, for completion of the pneumonectomy. The only exception is the study by Fujino and coworkers, who chose to start the procedure with the left thoracoscopy and pneumonectomy first, since an evaluation of tumor extension into the aortopulmonary window was deemed necessary (7).

For the left VATS phase, there is a trend towards a reduced number of thoracoscopic ports in more recent reports, which is explainable by the wider adoption and the growing confidence in both VATS pneumonectomy and uniportal surgery worldwide (9). Uniportal pneumonectomy, in the present case, was completed without added difficulties in 95 minutes. During this second phase, the newly performed anastomosis underwent the mechanical stress of positive pressure ventilation, which was supplied through a standard single-lumen tube; thus, keeping operative time as short as possible was fundamental.

Most investigators have relied upon cross-field intubation during carinal resection and anastomosis, while Yen et al. have reported the use of high frequency jet ventilation (HFJV) for this purpose (3). We believe that both options are feasible. In fact, despite early concerns that the use of HFJV in patients undergoing TSP could result in an increased rate of acute respiratory distress syndrome (2), later case-series have not confirmed these findings $(10,11)$. 
As for the choice of the lung to ventilate, intubation of the left main bronchus allows for an undisturbed procedure of resection and anastomosis, without intermittent apnea; however, this option depends on the possibility of preoperative endoscopic debulking of the airway and on the functional condition of the affected left lung.

Although the patients' number is low and there is potential for publication bias, overall, the postoperative outcomes of the reported cases seem favorable. Only one patient died in the postoperative period (6), due to a presumed respiratory tract bleeding, while two patients experienced complications that resulted in a prolonged hospital stay $(3,7)$.

\section{Conclusions}

To conclude, the growing number of reports suggests that the bilateral combined open and thoracoscopic approach herein presented is feasible, and that it should be considered as an alternative to median sternotomy or to other traditional approaches for selected, more complicated cases of LTSP.

\section{Acknowledgments}

Funding: None.

\section{Footnote}

Provenance and Peer Review: This article was commissioned by the the editorial office, Fournal of Visualized Surgery for the series "Alternative Surgical Approaches for Challenging Cases in Thoracic Surgery". The article has undergone external peer review.

Reporting Checklist: The authors have completed the CARE reporting checklist. Available at https://jovs.amegroups. com/article/view/10.21037/jovs-2020-10/rc

Conflicts of Interest: All authors have completed the ICMJE uniform disclosure form (available at https://jovs.amegroups. com/article/view/10.21037/jovs-2020-10/coif). The series "Alternative Surgical Approaches for Challenging Cases in Thoracic Surgery" was commissioned by the editorial office without any funding or sponsorship. FR served as the unpaid Guest Editor of the series and serves as an unpaid editorial board member of Fournal of Visualized Surgery from August 2019 to July 2021. The authors have no other conflicts of interest to declare.
Ethical Statement: The authors are accountable for all aspects of the work in ensuring that questions related to the accuracy or integrity of any part of the work are appropriately investigated and resolved. All procedures performed in this study were in accordance with the Helsinki Declaration (as revised in 2013). Written informed consent was obtained from the patient for publication of this study and any accompanying images.

Open Access Statement: This is an Open Access article distributed in accordance with the Creative Commons Attribution-NonCommercial-NoDerivs 4.0 International License (CC BY-NC-ND 4.0), which permits the noncommercial replication and distribution of the article with the strict proviso that no changes or edits are made and the original work is properly cited (including links to both the formal publication through the relevant DOI and the license). See: https://creativecommons.org/licenses/by-nc-nd/4.0/.

\section{References}

1. de Perrot M, Fadel E, Mercier O, et al. Long-term results after carinal resection for carcinoma: does the benefit warrant the risk? J Thorac Cardiovasc Surg 2006;131:81-9.

2. Porhanov VA, Poliakov IS, Selvaschuk AP, et al. Indications and results of sleeve carinal resection. Eur J Cardiothorac Surg 2002;22:685-94.

3. Yen YT, Lai WW. Right thoracotomy for carinal resection with left thoracoscopic pneumonectomy as a new approach for left sleeve pneumonectomy: a case report. Kaohsiung J Med Sci 2010;26:609-14.

4. Tse DG, Vadehra N, Iancu L. Left tracheal sleeve pneumonectomy: a combined approach. J Thorac Cardiovasc Surg 2005;129:454-5.

5. Weder W, Inci I. Carinal resection and sleeve pneumonectomy. Thorac Surg Clin 2014;24:77-83.

6. Ai B, Liao Y, Zhang Z, et al. Single-stage bilateral thoracic surgery via a combined VATS and open approach for left central bronchogenic carcinoma with carinal invasion: report of two cases. J Cardiothorac Surg 2015;10:76.

7. Fujino $T$, Tanahashi $M$, Yukiue $H$, et al. A new approach to left sleeve pneumonectomy: complete VATS left pneumonectomy followed by right thoracotomy for carinal resection and reconstruction. Surg Case Rep 2018;4:91.

8. Aim A, Almre I, Vanakesa T. Combined approach using uniportal video-assisted thoracoscopic surgery in left tracheal sleeve pneumonectomy. J Thorac Dis 2018;10:E584-6. 
9. Nagai S, Imanishi N, Matsuoka T, et al. Video-assisted thoracoscopic pneumonectomy: retrospective outcome analysis of 47 consecutive patients. Ann Thorac Surg 2014;97:1908-13.

10. Regnard JF, Perrotin C, Giovannetti R, et al. Resection for tumors with carinal involvement: technical aspects, results,

doi: 10.21037 /jovs-2020-10

Cite this article as: Mammana M, Comacchio GM, Pangoni A, Zuin A, Nicotra S, Giraudo C, Rea F. Combined right thoracotomy and left video-assisted thoracoscopic surgery for left tracheal sleeve pneumonectomy: a case report. J Vis Surg 2021;7:32. and prognostic factors. Ann Thorac Surg 2005;80:1841-6.

11. Rea F, Marulli G, Schiavon M, et al. Tracheal sleeve pneumonectomy for non small cell lung cancer (NSCLC): short and long-term results in a single institution. Lung Cancer 2008;61:202-8. 